\title{
Dispersion characterization of chalcogenide bulk glass, composite fibers, and robust nanotapers
}

\author{
Soroush Shabahang, Guangming Tao, Joshua J. Kaufman, and Ayman F. Abouraddy* \\ CREOL, The College of Optics \& Photonics, University of Central Florida, Orlando, Florida 32816, USA \\ *Corresponding author: raddy@creol.ucf.edu
}

Received April 19, 2013; revised July 17, 2013; accepted August 6, 2013; posted August 7, 2013 (Doc. ID 189138); published August 26, 2013

\begin{abstract}
We report the results of systematic measurements of the group velocity dispersion (GVD) in chalcogenide glass (ChG) bulk samples, composite ChG fibers, and robust high-index-contrast nanotapers. The composite ChGpolymer fibers are drawn from an extruded multimaterial preform incorporating a thick built-in polymer jacket that is thermally compatible with the ChG used, and the nanotapers are then produced without removing the polymer. We isolate the contributions of material and waveguide GVD to the total dispersion in the nanotapers and support the results with finite-element simulations. These results indicate many possibilities for dispersion engineering and nonlinearity enhancement in all-solid index-guiding ChG fibers stemming from the flexibility of this fiber fabrication methodology. (C) 2013 Optical Society of America
\end{abstract}

OCIS codes: (060.0060) Fiber optics and optical communications; (120.0120) Instrumentation, measurement, and metrology; (160.0160) Materials. http://dx.doi.org/10.1364/JOSAB.30.002498

\section{INTRODUCTION}

Chalcogenide glasses (ChGs) [1] are endowed with several salutary features that make them excellent candidates for applications in midinfrared (MIR) nonlinear fiber optics. ChGs may be stably drawn into fibers [2,3], are transparent in the MIR [1] , have higher nonlinear coefficients than typical oxide glasses [4-9], and have low two-photon absorption [10,11]. This potential is thwarted, however, by the mechanical fragility of ChGs [12] and their large normal group velocity dispersion (GVD) in the infrared [13], which distorts ultrashort optical pulses [14] and reduces the effective optical nonlinearity [15]. Furthermore, in some applications, such as supercontinuum generation, the GVD sign and magnitude play a crucial role, and hence must be precisely controlled [16,17].

To harness the useful features of ChGs in MIR nonlinear fiber optics, both of these issues (mechanical fragility and dispersion control) must be addressed. Several approaches have been pursued to obviate the high bulk-ChG GVD through engineering the waveguide dispersion. In one approach, ChG photonic crystal fibers (PCFs) [18,19] have been developed for GVD control [20]. The difficulty of ChG processing, in addition to the steeper viscosity-temperature dependence that is shifted to a much lower temperature for ChGs compared to that of silicates $[\underline{21}, \underline{22}]$, have made progress along these lines slow since it is difficult to precisely and uniformly control the nanoscale trusses and wires required in the PCF cladding. An alternative approach relies on fiber tapering to modify GVD through dimensional control [23,24] or hanging-core ChG fibers $[19,25]$. Tapering also enhances the nonlinearity by increasing field confinement in high-index-contrast structures [26] but is hampered by the unfavorable mechanical properties of ChGs [12].

We have recently reported a new approach for fabricating composite ChG-polymer preforms from which robust ChG fibers are drawn: one-step multimaterial preform coextrusion [27]. This process produces ChG preforms provided with a thick built-in thermoplastic polymer jacket that is thermally compatible with the ChG. This feature has important consequences for the prospects of ChG fibers. First, the built-in polymer jacket improves the mechanical strength of the fiber with respect to both bending and extensional forces [27]. Second, since the ChG and polymer are thermally compatible, the drawn fiber may be tapered without removing the polymer jacket [28-30]. Third, the process facilitates the fabrication of fibers with large core/cladding index contrasts ( $\left(n_{\text {core }}-\right.$ $\left.n_{\text {clad }}\right) /\left(n_{\text {clad }}\right) \approx 0.15$ in [27] $)$. This procedure thus yields a new generation of $\mathrm{ChG}$ fibers that alleviates the traditional concerns of their mechanical strength and simultaneously opens up routes to new designs for GVD control and nonlinearity enhancement.

In this paper we present the results of systematic measurements of the GVD parameter $\beta_{2}[\underline{15}]$ at wavelength $\lambda=1.5 \mu \mathrm{m}$ in bulk ChGs, in high-index-contrast composite ChG fibers produced by the above-described process, and in robust ChG nanotapers. We measure $\beta_{2}$ using spectral interferometry [31] after each fabrication step in order to detect potential effects attributed to the specific thermal processing associated with this new fiber production methodology. We isolate the contribution of waveguide dispersion and find excellent agreement with calculated values across both normal and anomalous waveguide dispersion regimes. Furthermore, we measure GVD in bulk ChGs at $\lambda=2 \mu \mathrm{m}$ to assess the utility of thulium fiber lasers that are emerging as a potential pump source for MIR nonlinear fiber optics [32-36]. By combining the bulk $\beta_{2}$ measurements at $\lambda=2 \mu \mathrm{m}$ with calculated waveguide GVD, we present designs for all-solid zero-GVD ChG fibers.

This study is further motivated by the scarcity of reported direct GVD measurements in ChGs. Typically, ChG GVD is 
estimated from the measured wavelength-dependent refractive index $\left(\mathrm{As}_{2} \mathrm{Se}_{3}\right.$ in [37] and $\mathrm{As}_{2} \mathrm{~S}_{3}$ in [38]), carried out recently using ellipsometry [39] and the prism-coupling technique [40]. The only reports on direct measurement of $\beta_{2}$ in ChGs are for bulk $\mathrm{As}_{2} \mathrm{~S}_{3}$ at $1.3 \mu \mathrm{m}$ [41]; $\mathrm{As}_{2} \mathrm{Se}_{3}$ fiber [42]; $\mathrm{As}_{2} \mathrm{Se}_{3}, \mathrm{Ge}_{15} \mathrm{Sb}_{20} \mathrm{~S}_{65}$ [43]; and $\mathrm{As}_{2} \mathrm{~S}_{3}$ [ㄴ4] microstructured fibers at $1.5 \mu \mathrm{m}$. Moreover, since short, few-centimeter-long tapers are expected to be particularly important in MIR supercontinuum generation [23], it is crucial to accurately assess the effect of tapering on ChG fiber GVD. To the best of our knowledge, there have been no reported GVD measurements in ChG tapers. The results presented here on direct $\beta_{2}$ measurements in bulk samples, fibers, and nanotapers help close that gap. We present the results of nonlinear characterization of these fibers and nanotapers elsewhere [30,45].

This paper is organized as follows. We first briefly describe our fiber fabrication methodology (details are delegated to Appendix A) and highlight the unique aspects of tapering dynamics for a hybrid ChG/polymer fiber compared to tapering all-glass fibers. After we review the field confinement for the fundamental mode as we reduce the hybrid fiber diameter, we describe the optical setup used to measure $\beta_{2}$ via spectral interferometry. We then present our measurement results for bulk, fiber, and nanotaper samples. Finally, we use the measurement parameters to provide potential designs for all-solid zero-GVD ChG fibers. These results will be useful in the design of future ChG-fiber-based MIR optical sources based on nonlinear interactions.

\section{BULK, FIBER, AND NANOTAPER SAMPLE PREPARATION AND CHARACTERIZATION}

Bulk samples of three ChG glass compositions were prepared: $\mathrm{G}_{1}, \mathrm{As}_{2} \mathrm{Se}_{3} ; \mathrm{G}_{2}, \mathrm{As}_{2} \mathrm{Se}_{1.5} \mathrm{~S}_{1.5}$; and $\mathrm{G}_{3}, \mathrm{As}_{2} \mathrm{~S}_{3}$ (Fig. 1). See Appendix A for processing details. These three ChGs have high third-order optical nonlinearity [4-9] and their stable thermo-mechanical properties allow for thermal drawing into fibers [2,3]. The samples were prepared in the form of 10 and $30 \mathrm{~mm}$ diameter cylindrical rods that we used for bulk GVD measurements and for subsequent fiber-preform extrusion, respectively. We determined the transparency windows of these ChGs using an FTIR spectrometer (Bruker Tensor 37) in the spectral range $0.5-20 \mu \mathrm{m}$ [see Fig. 1(a)]. We note the gradual shift of the absorption band edges to longer wavelengths as Se replaces $\mathrm{S}$ in the glass matrix at both the long-wavelength [Fig. 1(a)] and short-wavelength [Fig. 1(b)] ends.

Unlike the "double-crucible" approach to ChG fiber drawing $[46,47]$, in which the fiber is drawn from two melts of the core and cladding glasses in an inert atmosphere, we draw our fibers from a preform in the ambient environment. We produced three preforms. Preforms I and II were fabricated by one-step multimaterial coextrusion [27]. Preform-I consists of a $\mathrm{G}_{1}$ core, a $\mathrm{G}_{3}$ cladding, and a polyetherimide (PEI) built-in protective jacket with diameter ratios $\mathrm{G}_{1}: \mathrm{G}_{3}: \mathrm{PEI}=$ 2.5:7.5: $12 \mathrm{~mm}$. Preform-II consists of a $\mathrm{G}_{2}$ core, a $\mathrm{G}_{3}$ cladding, and a polyethersulfone (PES) jacket with diameter ratios $\mathrm{G}_{2}: \mathrm{G}_{3}: \mathrm{PES}=2.5: 8.75: 12 \mathrm{~mm}$. The core/cladding diameter ratio and the glass compositions used may be readily varied by changing the structure of the extrusion billet and the design of the die [27]. In addition, we measured the optical transmission of a typical thermoplastic polymer PES, used in the fibers as a protective jacket [see Fig. 1(c)]. As is clear, PES is highly
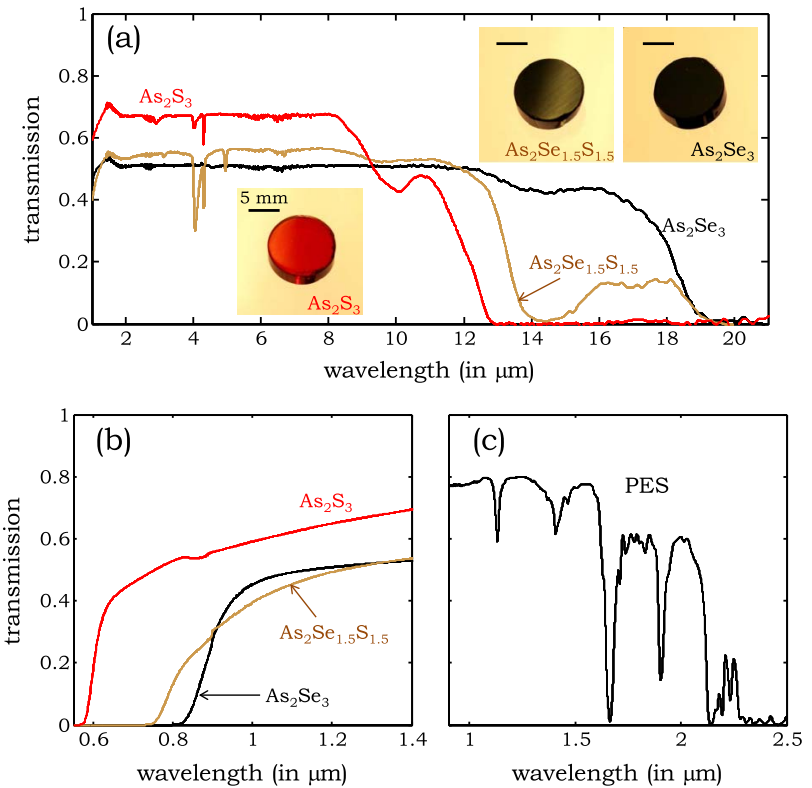

Fig. 1. (a) FTIR transmission spectra for three ChG samples. $\mathrm{G}_{1}: \mathrm{As}_{2} \mathrm{Se}_{3} ; \mathrm{G}_{2}: \mathrm{As}_{2} \mathrm{Se}_{1.5} \mathrm{~S}_{1.5} ;$ and $\mathrm{G}_{3}: \mathrm{As}_{2} \mathrm{~S}_{3}$. Each sample is a $10-\mathrm{mm}-$ diameter disc of thickness $\approx 2 \mathrm{~mm}$. Insets show photographs of the samples; all scale bars are $5 \mathrm{~mm}$. (b) FTIR transmission spectra showing the low-wavelength cutoff for $G_{1}, G_{2}$, and $G_{3}$. (c) FTIR transmission spectrum for a 2-mm-thick polymer sample; PES, polyethersulfone.

absorptive in the MIR. In designing such fibers, care must thus be taken to minimize the fraction of light reaching the polymer. Finally, Preform-III consists of a $\mathrm{G}_{1}$ core and a PES cladding prepared by rolling a $125-\mu$ m-thick PES film around a $10 \mathrm{~mm}$ diameter, $10 \mathrm{~cm}$ long $\mathrm{G}_{1}$ glass rod [48-50].

Preforms I and II were drawn into canes $\approx 150 \mu \mathrm{m}$-corediameter. A thin-polymer-film is rolled around the cane (PEI for Preform I and PES for Preform II) and then thermally consolidated under vacuum. A new preform is thus produced that is drawn into a fiber with core diameter $10 \mu \mathrm{m}$, cladding diameter $30 \mu \mathrm{m}$, and outer diameter $1 \mathrm{~mm}$ for Fiber I, and core diameter $10 \mu \mathrm{m}$, cladding diameter $35 \mu \mathrm{m}$, and outer diameter $1.2 \mathrm{~mm}$ for fiber II [Figs. 2(a) and 2(b)]. Fiber III consists of a $10 \mu \mathrm{m}$ diameter $\mathrm{G}_{1}$ core and a $1 \mathrm{~mm}$ diameter PES jacket [Figs. 2(c) and 2(d)]. The final core diameter in all fibers is controlled during fiber drawing and is typically maintained at $10 \mu \mathrm{m}$. We point out for completeness recent efforts on providing ChG fibers with a polymer coating through collapsing a [poly(methyl methacrylate), PMMA], jacket around a prefabricated ChG fiber [51].

We produced fiber nanotapers using Fiber-II without removing the polymer using a home-built tapering system (a)

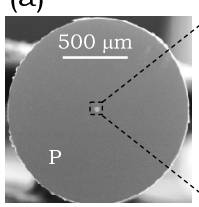

(b)

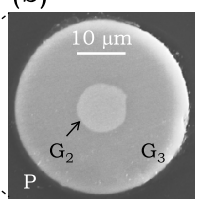

(c)

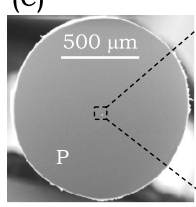

(d)

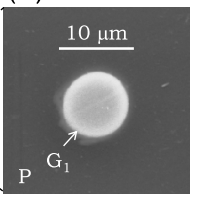

Fig. 2. Scanning electron microscope (SEM) images of Fiber II (a) full cross section and (b) ChG core/cladding region; and Fiber III. (c) Full cross section and (d) ChG core region. P: Polyethersulfone (PES). $\mathrm{G}_{1}: \mathrm{As}_{2} \mathrm{Se}_{3} ; \mathrm{G}_{2}: \mathrm{As}_{2} \mathrm{Se}_{1.5} \mathrm{~S}_{1.5} ;$ and $\mathrm{G}_{3}: \mathrm{As}_{2} \mathrm{~S}_{3}$. 
Tension: $40 \mathrm{~g}$; Heating time: $40 \mathrm{~s}$

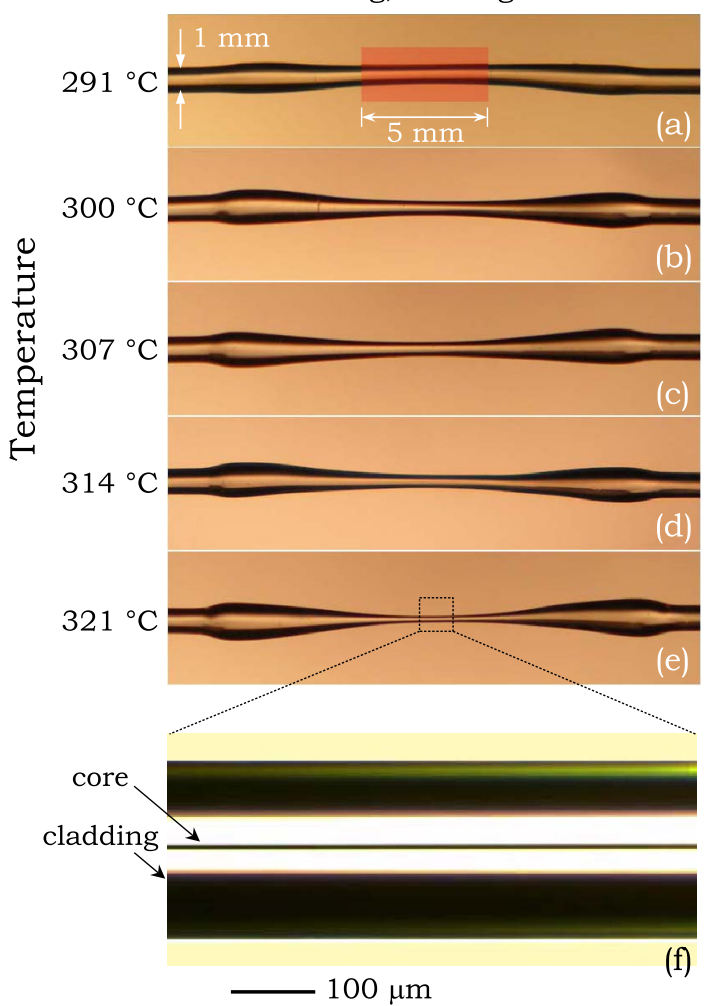

Fig. 3. Fiber axial plastic deformation upon heating in a tapering setup with $5 \mathrm{~mm}$ wide uniform heating zone-corresponding to the red rectangle in panel (a). Panels (a) through (e) are transmission optical micrographs that correspond to identical samples (Fiber III, equivalent drawing tension of $40 \mathrm{~g}$ ) at different temperatures for $40 \mathrm{~s}$. Initial fiber outer diameter is $1 \mathrm{~mm}$. (f) Transmission optical micrograph showing a magnified side image of the intact $G_{1}$ core inside the PES cladding. The black symmetric outer portions of the cladding in the microscope image result from the curvature of the taper outer surface.

[28], which allows us to exercise considerable control over the taper axial profile and results in robust nanotapers. Although glass-fiber tapering has been studied extensively [52], our ChG-polymer hybrid fiber reveals different tapering dynamics since the polymer, which is the principal material component in the fiber, dictates its mechanical properties. Upon heating, the stress stored in the fiber polymer cladding during drawing and associated axial elongation (resulting in molecular alignment in the polymer) is released in the heated section. During fiber drawing, tension is determined in grams (equivalent force) by a force meter that measures the restoring force from the fiber being pulled. The tension is determined by the drawing temperature, the drawing speed, and the downfeed speed of the preform into the draw-tower furnace.

Consequently, the polymer undergoes plastic deformation and shrinks away from the heating zone to accumulate at its edges (Fig. 3). At the center of each sample, the fiber diameter is reduced the most (the minimum core diameter at the midpoint is referred to hereafter as $d_{\text {min }}$ ), producing a tapered shape along the axis. Sectioning the fiber at different positions along the taper axis and examining the cross sections reveals that the core diameter scales approximately at a constant ratio with the outer diameter. As a result, we will take the axial variation of the fiber outer diameter along the nanotapers to be an indication of their core diameters.

We find that the size and shape of the swelling or bulges thus formed depend on both the tapering parameters and the fiber-drawing tension. To study the effect of tapering temperature on the polymer swelling, we prepared five identical fiber samples drawn under $40 \mathrm{~g}$ equivalent tension and mounted them with fixed ends in a $20 \mathrm{~mm}$ long heating zone (5 mm long uniform heating section) and heated them for $40 \mathrm{~s}$ at different temperatures without pulling the sample ends (Fig. 3). It is clear that as the tapering temperature increases, the deformation in turn increases. In another experiment, samples from three fibers-that were drawn under different tension-were heated at fixed temperature, and fiber deformation was observed in real time (Fig. 4). Our observations confirm that plastic deformation is more pronounced for a fiber drawn under higher tension. To reduce the effect of plastic deformation during tapering, we subsequently draw the fibers at low tension. Now, by also applying axial pulling force during tapering, we may control the length of the produced taper while maintaining minimal deformation at the edges.

The unique aspect of the polymer jacket is that it enables tapering the samples, thereby reaching submicrometerdiameter cores while remaining robust enough for convenient handling. For example, the taper shown in Fig. 5(a) with $400 \mathrm{~nm}$ core diameter has a $\approx 50 \mu \mathrm{m}$ outer diameter. Moreover, in [29] we demonstrate stable tapering of a polymerembedded $\mathrm{G}_{1}$ ChG nanowire to sub $5 \mathrm{~nm}$ diameter. In our optical characterization experiments, we typically cut the tapered section of the fiber, fix it on a glass slide using epoxy,

Temperature: $307^{\circ} \mathrm{C}$

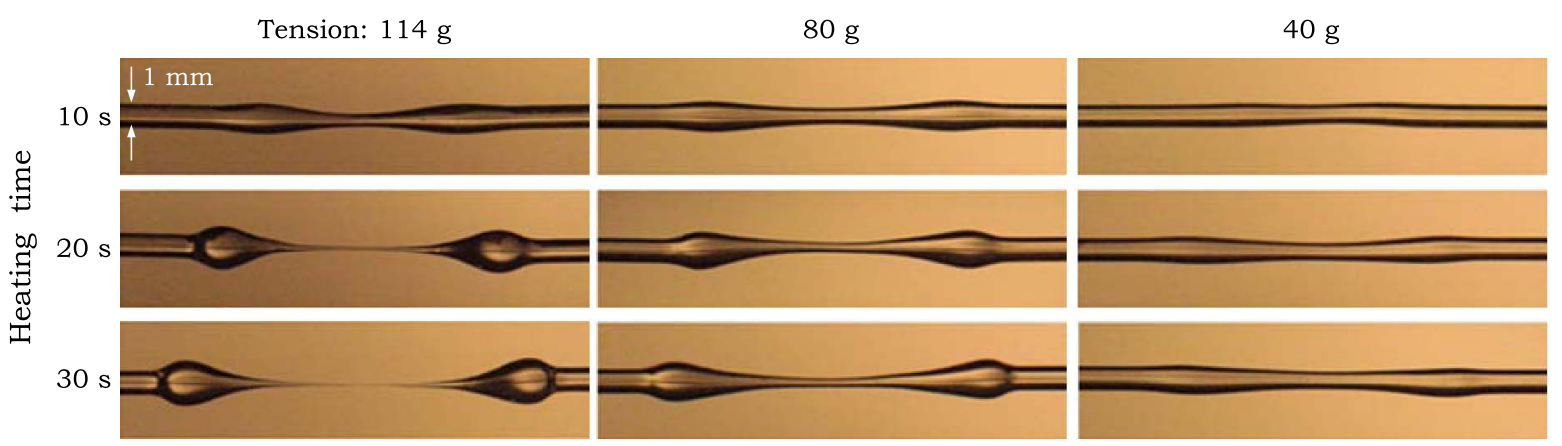

Fig. 4. Dependence of the axial plastic deformation upon heating in a tapering setup (see Fig. 3) on the tension during fiber drawing and tapering time. Each panel is an optical transmission micrograph of a fiber sample with initial fiber outer diameter $1 \mathrm{~mm}$. The tapering temperature is held fixed throughout and the fiber-drawing tension is constant in each column. 

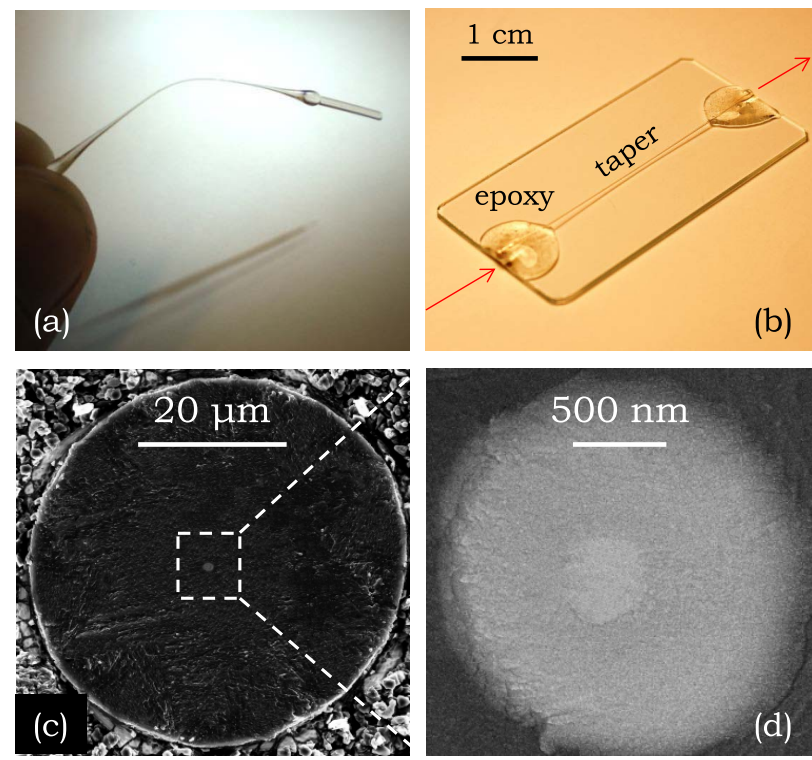

Fig. 5. (a) Robust nanotaper with minimum core midway along the sample $d_{\min }=400 \mathrm{~nm}$. (b) Nanotaper mounted on a glass slide and is fixed using epoxy, after which the facets are polished. (c) SEM micrograph of the nanotaper cross section at the taper mid-point (corresponding to minimum diameter). (d) Higher-magnification SEM micrograph highlighting the ChG core/cladding structure; compare to Fig. 2(b). Note the increase in the apparent ChG cladding size due to smearing of the ChG/polymer interface that occurs during surface polishing in preparation for SEM imaging.

and then polish the facets [Fig. 5(b)]. A section through the midpoint of such a taper [Figs. $\underline{5(\mathrm{c})}$ and $\underline{5(\mathrm{~d})}$ ] reveals that the fiber structure is maintained.

Finally, we note that care must be taken during tapering to avoid the onset of fluid instabilities, such as the PlateauRayleigh capillary instability, that may be induced during tapering when the ChGs are in a low-viscosity state. Such a fluid instability may result in the breakup of the continuous ChG core into isolated spheres held stationary in the polymer cladding $[28,53]$. We have reported elsewhere [28] the restrictions on tapering speed and temperature that enable us to avoid such phenomena and obtain axially continuous nanotapers.

\section{OPTICAL CONFINEMENT IN ChG-POLYMER NANOTAPERS}

As the core diameter decreases, transmitted light becomes less-confined to the core. Therefore, while tapering first reduces the mode diameter, and hence increases the intensity, eventually the mode spreads out and the intensity drops with further reduction in core diameter. We used COMSOL to determine the reduction in field confinement of the fundamental mode with decrease in diameter [Fig. 6(a)], maintaining the relative dimensions of the Fiber II structure. At $\lambda=1.55 \mu \mathrm{m}$, core diameters of $1 \mu \mathrm{m}, 500 \mathrm{~nm}$, and $250 \mathrm{~nm}$ result in confining $\approx 80 \%, 50 \%$, and $20 \%$ of the fundamental mode to the core, respectively. In the latter case where the least amount of light is confined to the core, $6 \%$ of the beam resides in the polymer layer, thereby increasing the infrared transmission losses [see Fig. 1(a)]. Therefore, for MIR applications, the fiber structure must be modified by increasing the ChG cladding diameter to minimize the percentage of light reaching the polymer. (a)

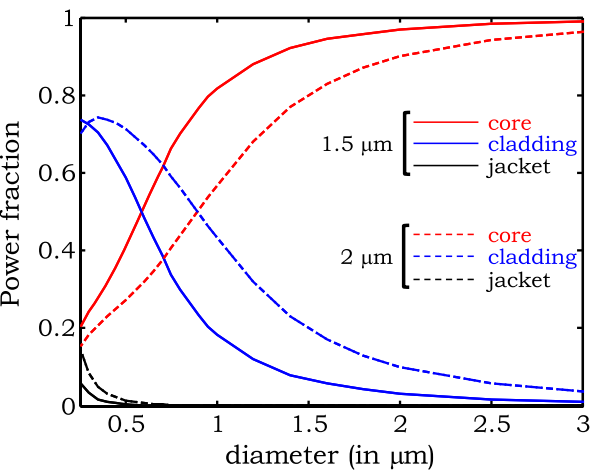

(b)

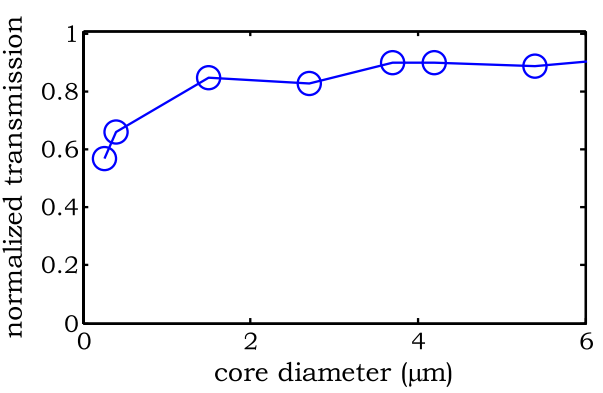

Fig. 6. (a) Fraction of light in the core, cladding, and polymer jacket in a structure corresponding to Fiber II while changing the core diameter for both $\lambda=1.55$ and $1.95 \mu \mathrm{m}$. The fractions were computed assuming the measured indices given in Table 1 and the ratio of diameters core: cladding $=1: 3.5$, as shown in Fig. $2(\mathrm{~b})$. The polymer jacket was assumed infinite. At larger diameters (not shown), the fundamental mode is mostly confined to the core. (b) Transmission loss of $\lambda=1.55 \mu \mathrm{m}$ laser light in $25 \mathrm{~mm}$ long tapers with different diameters-normalized to the transmission in an equal length of non-tapered fiber.

Measurements of the optical transmission of $1.55 \mu \mathrm{m} \mathrm{CW}$ laser light in several $25 \mathrm{~mm}$ long tapers and different core diameters is shown in Fig. $\underline{6(b)}$. When the core diameter is reduced below $1.5 \mu \mathrm{m}$, the transmission is significantly reduced. One potential reason is that local scattering centers in the glass matrix play a more significant role here than they usually play in the larger-diameter fibers before tapering.

\section{DISPERSION CHARACTERIZATION}

\section{A. Measurement Setup and Procedure}

Fiber dispersion measurement techniques may be classified as pulse-delay (or time-of-flight), phase-shift, or interferometric methods. The pulse-delay technique is suitable for large group delays by determining the differential delay between optical pulses of different wavelengths [54,55]. This method is typically used for long fibers, but recent efforts have extended it to shorter lengths $[56,57]$. In the phase-shift method, sinusoidally modulated broadband light is coupled to the fiber and the delay between two selected wavelengths is extracted from their relative phase shift, subject to phase-wrapping ambiguities [58]. Interferometry resolves group delays down to $0.1 \mathrm{fs}$ and is thus suitable for short fiber samples [59,60].

We measured $\beta_{2}$ here using spectral interferometry [31] in a single-mode-fiber-based Mach-Zehnder interferometer (MZI) with the sample placed in one arm (sample arm) and a fixed delay in the other (reference arm) [see Fig. 7]. The same procedure was used for measurements at $\lambda=\overline{1} .55$ and $1.95 \mu \mathrm{m}$, except for the use of a different light source and detector. Light input to a fiber coupler is split between the reference 


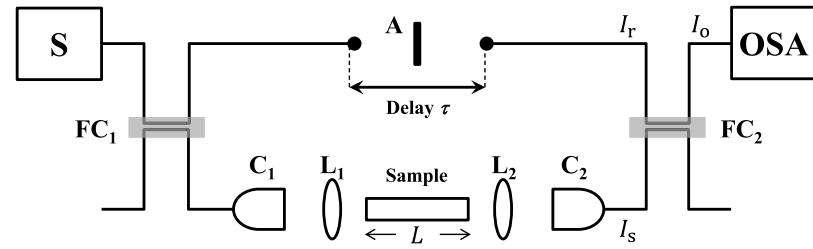

Fig. 7. Setup for measuring $\beta_{2}$. S, source; FC, fiber coupler; C, collimator; L, lens; A, attenuator (to increase fringe visibility); OSA, optical spectrum analyzer. Solid lines are single-mode fibers.

and sample arms of the MZI. In the reference arm we place a free-space optical delay $\tau$ and a variable attenuator. In the sample arm, light is coupled out of the SMF, is collimated, traverses the sample, and is then coupled back into a SMF fiber (Fig. 7). Three spectra were recorded for each sample by means of an optical spectrum analyzer (OSA): the sample spectrum $I_{\mathrm{s}}(\lambda)$ obtained by blocking the reference MZI arm; the reference spectrum $I_{\mathrm{r}}(\lambda)$ obtained by blocking the sample arm; and the output spectrum $I_{\mathrm{o}}(\lambda)$ obtained by superposing the sample and reference spectra.

The interference term was extracted from $I_{\mathrm{o}}, I_{\mathrm{s}}$, and $I_{\mathrm{r}}: \cos \Delta \varphi=\left(I_{\mathrm{o}}-I_{\mathrm{s}}-I_{\mathrm{r}}\right) /\left(2 \sqrt{I_{\mathrm{s}} I_{\mathrm{r}}}\right)$, where $\Delta \varphi=\varphi_{\mathrm{s}}-\omega \tau+\varphi_{\mathrm{B}}$; here $\tau$ is the delay, $\omega$ is the optical frequency, $\varphi_{\mathrm{B}}$ is a background phase estimated with the sample removed, and $\varphi_{\mathrm{s}}$ is the sample phase. We extract $\Delta \varphi$ versus wavelength directly from $\cos \Delta \varphi$, making use of the fact that the phase difference between each two successive peaks in $I_{0}(\lambda)$ is $2 \pi$. In order to accurately estimate the average wavelength difference between the peaks, amplitude modulation and noise were filtered from $I_{\mathrm{o}}(\lambda)$ in the Fourier domain [Figs. 8(a) and 8(b)]. This is particularly important when measurements are carried out at $2 \mu \mathrm{m}$ in order to discriminate against the fine atmospheric absorption lines that overlay the measured spectra [Figs. 8(d) and 8(e)]. We then estimate $\beta_{2}$ by fitting $\Delta \varphi$ to a second-order polynomial and averaging 10 measurements for each sample and then repeating the experiment at 6-8 different positive and negative delays [Figs. $\underline{8(\mathrm{c})}$ and 8(f)].

\section{B. Dispersion of Bulk Samples}

In the case of bulk samples in the form of $10 \mathrm{~mm}$ diameter ChG discs, light is collimated in free space by $\mathrm{C}_{1}$, traverses the sample and is then coupled back into an SMF via a second collimator $\mathrm{C}_{2}$ (lenses $\mathrm{L}_{1}$ and $\mathrm{L}_{2}$ are removed in this case; see Fig. 7). We measured $\beta_{2}$ at $\lambda=1.55 \mu \mathrm{m}$ and $1.95 \mu \mathrm{m}$ [see Fig. 8]. As a reference, we measured $\beta_{2}$ for a 1 in. cube of BK7 glass and compared it with those of the bulk ChG samples (Table 1). We find that GVD is normal and decreases with wavelength in the ChGs, while GVD is anomalous and increases with wavelength in BK7. This may be understood by noting that $\lambda=1.55 \mu \mathrm{m}$ is above the zero-dispersion wavelength of BK7 but below that of ChGs [37,38]. Note also the increase in GVD as Se replaces $\mathrm{S}$ in the $\mathrm{ChG}$ matrix.

We used the same setup to also measure the refractive index of the samples. The fringe spacing in $I_{\mathrm{o}}(\lambda)$ is longest when the optical path lengths are equal in both MZI arms. We adjust the optical delay in order to achieve this condition both in the presence and absence of the sample, from which we estimate the refractive index $n$ (with \pm 0.015 precision). The measured indices at $\lambda=1.55$ and $1.95 \mu \mathrm{m}$ are reported in Table 1 . Note the gradual increase in $n$ concomitant with that in $\overline{\beta_{2}}$ as Se replaces $\mathrm{S}$ in the ChG matrix.

To the best of our knowledge, these are the first direct measurement of GVD in ChGs at $1.95 \mu \mathrm{m}$. The measured GVD values here for $\lambda=1.55$ and $1.95 \mu \mathrm{m}$ are much larger than those associated with typical oxide glasses, which poses
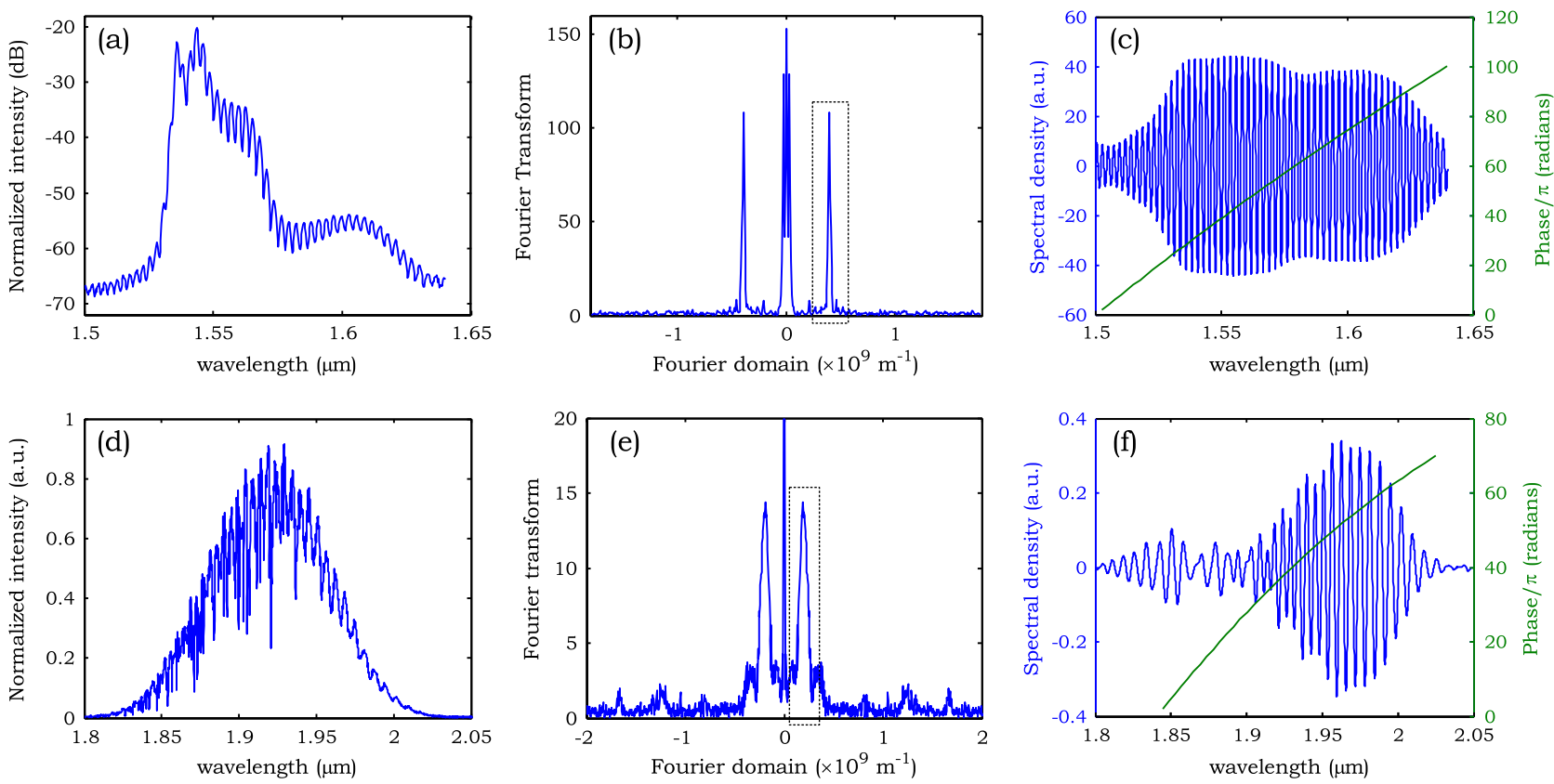

Fig. 8. (a) Spectral interference fringes in the output spectrum $I_{\mathrm{o}}(\lambda)$ (note the logarithmic vertical scale) obtained using an OSA (Advantest Q8381A). The sample here is the BK7 bulk cube and the source is amplified spontaneous emission (ASE) from an EDFA (EAU-200-c, IPG Photonics). (b) Fourier transform (FT) of $I_{\mathrm{o}}(\lambda)$. The black dashed box corresponds to the portion filtered out to extract the interference fringes. (c) Filtered spectral power density obtained by taking the inverse FT of (b) and the extracted spectral phase $\Delta \varphi(\lambda)$. (d)-(f) are similar to (a)-(c) except that the source is ASE from a thulium fiber laser, the OSA is Yokogawa AQ6375, and the sample used is a bulk As $\mathrm{S}_{3}$ disc; see Fig. 1(a), lower-left inset. 
Table 1. Measured Bulk Index $n$ and GVD $\beta_{2}$ in $\mathrm{ps}^{2} / \mathrm{km}$ at 1.55 and $1.95 \mu \mathrm{m}$ Wavelengths ${ }^{a}$

\begin{tabular}{lccccc}
\hline Sample & Glass & $n 1.55$ & $\beta_{2} 1.55$ & $n 1.95$ & $\beta_{2} 1.95$ \\
\hline Ref. & $\mathrm{BK} 7$ & 1.516 & -21 & - & -32 \\
G1 & $\mathrm{As}_{2} \mathrm{Se}_{3}$ & 2.904 & 978 & 2.876 & 762 \\
G2 & $\mathrm{As}_{2} \mathrm{Se}_{1.5} \mathrm{~S}_{1.5}$ & 2.743 & 670 & 2.645 & 554 \\
G3 & $\mathrm{As}_{2} \mathrm{~S}_{3}$ & 2.472 & 474 & 2.456 & 383 \\
\hline
\end{tabular}

${ }^{a}$ The indices $n$ are estimated within \pm 0.015 .

difficulties in using ultrafast pulses for nonlinear applications in ChG fibers. We shall use these measured values of $n$ and $\beta_{2}$ below to guide the design of zero-GVD all-solid ChG fibers.

\section{Dispersion of Fiber Samples}

The procedure used for bulk samples was also implemented for measuring the GVD in fiber samples, all of which have $10 \mu \mathrm{m}$ diameter cores. In this case, light collimated by $\mathrm{C}_{1}$ is then focused via a lens $L_{1}$ into the fiber. $C_{1}$ was chosen to match the fiber fundamental mode. The output light is collimated with a lens $\mathrm{L}_{2}$ (identical to $\mathrm{L}_{1}$ ) before being coupled back into an SMF fiber via collimator $\mathrm{C}_{2}$. Although the fiber samples are multimoded, we ensure that the measured $\beta_{2}$ is that of the fundamental mode by monitoring the existence of interference fringes in the sample spectrum $I_{\mathrm{s}}(\lambda)$ with the reference arm blocked, which reveals the potential excitation of multiple modes. The measured $\beta_{2}$ for $2.5 \mathrm{~cm}$ long fiber samples (Table 2) differ only slightly from the bulk core glass. This is expected from the small values of waveguide GVD predicted theoretically at large core diameters and large core-cladding index contrast [Fig. 9(b)]. We computed the waveguide GVD for the fundamental mode in COMSOL using the measured indices (Table 1) and structural dimensions for the fibers (Fig. 2). We then estimate the fiber GVD by combining the measured bulk GVD and calculated waveguide GVD, and find this estimate in good agreement with the measured fiber GVD for all three samples (see Table 2).

\section{Dispersion of Nanotaper Samples}

Finally we measured $\beta_{2}$ for the robust nanotapers prepared from Fiber II following the same procedure used for the fiber samples. The measured diameter profiles shown are given in Fig. 9(a), showing minimum core diameters $d_{\text {min }}$ at the nanotaper midpoints of $1.4 \mu \mathrm{m}, 600 \mathrm{~nm}, 400 \mathrm{~nm}$, and $330 \mathrm{~nm}$ (Table 3). The high index-contrast in conjunction with the large change in core diameter (starting from $10 \mu \mathrm{m}$ at the untapered end and extending down to $d_{\min }$ ) leads to very wide changes in local waveguide GVD along the taper. We measured the total GVD phase shift produced by the taper and then divided it by the taper length $L$ to obtain an average GVD parameter $\bar{\beta}_{2}$ (Table 3 ). We corroborate the measurements by computing $\bar{\beta}_{2}^{(\mathrm{sim})}=(1 / L) \sum_{j} \beta_{2}\left(z_{j}\right) \Delta z+\beta_{2}^{\mathrm{G}_{2}}$, where

Table 2. Measured (Meas.) and Simulated (Sim.) Fiber GVD $\beta_{2}$ at $1.55 \mu \mathrm{m}$ in $\mathrm{ps}^{2} / \mathrm{km}$; Jacket: Polymer Outer Jacket

\begin{tabular}{lccccc}
\hline Sample & Core & Clad. & Jacket & $\beta_{2}^{(\text {Meas })}$ & $\beta_{2}^{(\text {Sim })}$ \\
\hline Fiber I & $\mathrm{G}_{1}$ & $\mathrm{G}_{3}$ & PEI & 968 & 967.2 \\
Fiber II & $\mathrm{G}_{2}$ & $\mathrm{G}_{3}$ & PES & 685 & 659.4 \\
Fiber III & $\mathrm{G}_{1}$ & - & PES & 915 & 966.8 \\
\hline
\end{tabular}
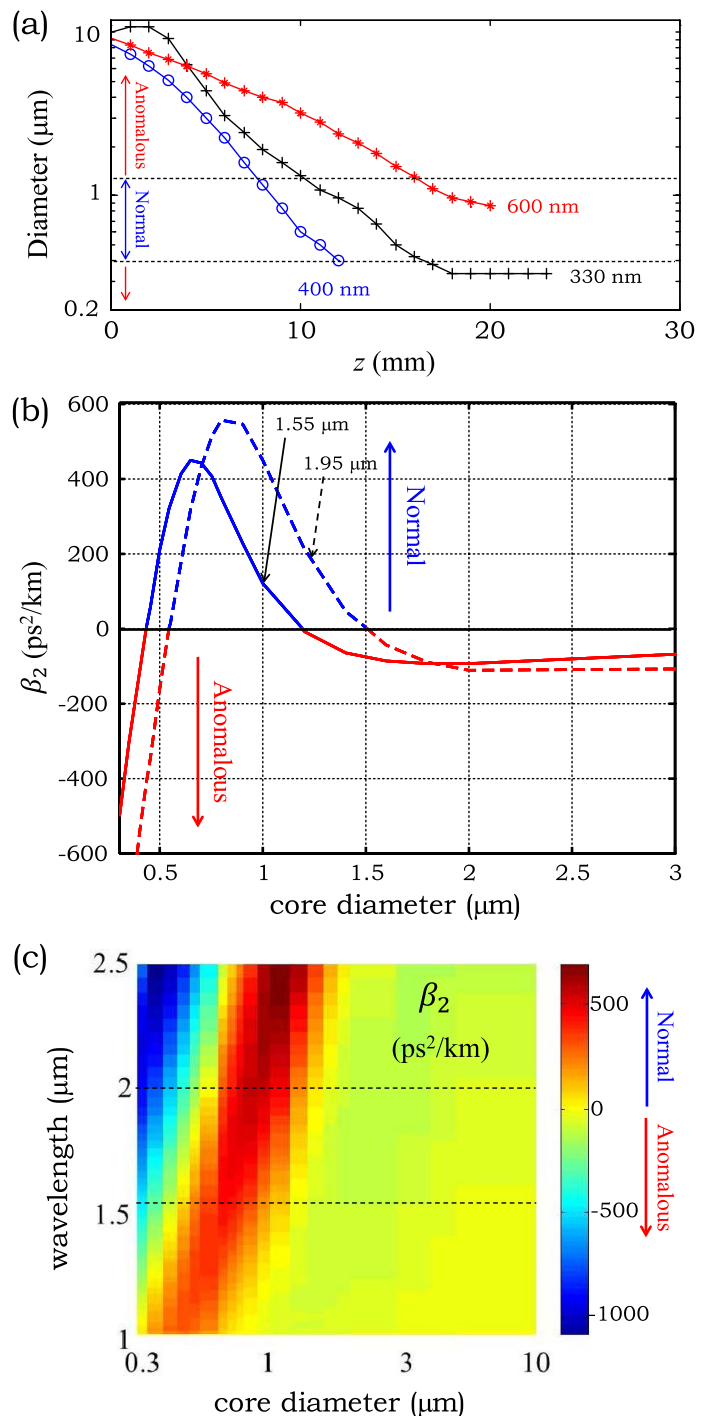

Fig. 9. (a) Measured diameter profile along the nanotapers' axes (Table 3). Only half the length of the tapers are shown. The other half of each profile is a mirror reflection around the midpoint. Diameter ranges corresponding to normal and anomalous GVD are identified. (b) Calculated waveguide $\beta_{2}$ for Fiber II at $\lambda=1.55 \mu \mathrm{m}$ and $\lambda=1.95 \mu \mathrm{m}$ for different core diameters. (c) Calculated waveguide $\beta_{2}$ as a function of core diameter and wavelength. The two horizontal dashed lines correspond to the wavelengths used in our measurements.

$\beta_{2}\left(z_{j}\right)$ is the local fundamental-mode waveguide GVD at $\lambda=1.55 \mu \mathrm{m}$ at positions $z_{j}$ along the taper separated by $\Delta z=1 \mathrm{~mm}$, and $\beta_{2}^{\mathrm{G}_{2}}$ is for the GVD of the bulk core glass $\mathrm{G}_{2}$. The dependence of waveguide GVD on the core diameter

Table 3. Measured (Meas.) and Simulated (Sim.) Average GVD $\beta_{2}$ at $1.55 \mu \mathrm{m}$ in $\mathrm{ps}^{2} / \mathrm{km}$ for Fiber-II Nanotapers

\begin{tabular}{lcccc}
\hline Sample & $d_{\min }$ & $L(\mathrm{~cm})$ & $\bar{\beta}_{2}{ }^{(\text {Meas })}$ & $\bar{\beta}_{2}{ }^{(\mathrm{Sim})}$ \\
\hline Taper I & $1.4 \mu \mathrm{m}$ & 2.1 & 640.8 & 621.4 \\
Taper II & $600 \mathrm{~nm}$ & 3.7 & 817.0 & 801.4 \\
Taper III & $600 \mathrm{~nm}$ & 4.25 & 752.3 & 731.6 \\
Taper IV & $400 \mathrm{~nm}$ & 2.5 & 631.8 & 692.8 \\
Taper V & $330 \mathrm{~nm}$ & 4.9 & 640.6 & 676.1 \\
\hline
\end{tabular}


and wavelength is shown in Figs. $\underline{9(\mathrm{~b})}$ and $9(\mathrm{c})$. The waveguide GVD at $1.55 \mu \mathrm{m}$ alternates with decreasing $D$ from anomalous $(1.2 \mu \mathrm{m}<d)$ to normal $(0.4<d<1.2 \mu \mathrm{m})$ and then anomalous $(d<400 \mathrm{~nm})$. The second anomalous range is due to the interaction of the extended field tail of the fundamental mode in the ChG cladding with the polymer jacket. By combining the measured diameter profiles along the nanotaper axes [Fig. 9(a)] with the calculated diameter-dependent $\beta_{2}$ [Fig. 9(b)], we estimate $\beta_{2}\left(z_{j}\right)$, from which we obtain the average $\bar{\beta}_{2}$. The measured and calculated $\bar{\beta}_{2}$ are in good agreement (Table 3). The results highlight the importance of the axial taper profile on engineering the nanotaper dispersion.

\section{DESIGNS FOR ALL-SOLID ZERO-GVD ChG FIBERS}

The ability of our fabrication process [27] to produce a highindex-contrast core/cladding fiber structures opens the possibility of GVD control-necessary in most nonlinear wavelength conversion applications-using a simple all-solid structure. Using the measured indices and GVD parameters, we present examples of core-cladding structures that achieve zero-GVD in the infrared. First, consider the Fiber-II structure investigated above, but assuming an infinite $\mathrm{G}_{3}$ cladding (no polymer jacket). A core diameter of $d=4 \mu \mathrm{m}$ achieves zeroGVD in the spectral range $\lambda=3.1-3.2 \mu \mathrm{m}$ (assuming a linear drop in bulk GVD with wavelength). In order to achieve zeroGVD at shorter wavelengths, a higher index-contrast is necessary. One approach is to use a tellurite glass cladding $n=2.1$, which produces zero-GVD at 2.2-2.3 $\mu \mathrm{m}$ (close to the thuliumfiber laser operating wavelength) with $d=1.4 \mu \mathrm{m}$ for either a $\mathrm{G}_{1}$ or $\mathrm{G}_{2}$ core. In other words, by controlling parameters that are accessible to our fabrication procedure $\left(n_{\text {core }}, n_{\text {cladding, }}\right.$, and $d$ ), we may shift the zero-dispersion wavelength to the near-infrared where high-power laser sources are available.

\section{CONCLUSION}

In conclusion, we have presented systematic GVD measurements in ChG bulk samples, short lengths of high-indexcontrast composite ChG fibers and robust nanotapers utilizing spectral interferometry. The fibers are drawn from preforms produced by a recently developed process, one-step multimaterial preform coextrusion, and our results confirm that the multiple thermal cycling involved in this methodology does not change the material dispersion. Furthermore, our results indicate that engineering the GVD through index-profile design and the fiber/taper geometry may enable zero-GVD high-indexcontrast all-solid ChG fibers [27] for MIR nonlinear fiber optics.

\section{APPENDIX A}

Bulk glass samples are prepared from commercial glass (Amorphous Materials, Inc.) by melt-quenching [21,61]. The as-purchased glass (typically 10-150 g) is crushed into small pieces with average size $<10 \mathrm{~mm}$ and loaded into a silica ampoule, which is evacuated $\left(10^{-4} \mathrm{~Pa}\right)$ and sealed with a propane-oxygen flame. The $\mathrm{ChG}$ is melted in a rocking furnace at $900^{\circ} \mathrm{C}-950^{\circ} \mathrm{C}$ for $12 \mathrm{~h}$, quenched in cold water, and then annealed near the glass-transition temperature for $2-5 \mathrm{~h}$ to produce 10 and $30 \mathrm{~mm}$-diameter glass rods for bulk measurements and fiber preform extrusion, respectively. Three glass compositions were investigated: $\mathrm{G}_{1}, \mathrm{As}_{2} \mathrm{Se}_{3} ; \mathrm{G}_{2}$, $\mathrm{As}_{2} \mathrm{Se}_{1.5} \mathrm{~S}_{1.5}$; and $\mathrm{G}_{3}, \mathrm{As}_{2} \mathrm{~S}_{3} . \mathrm{G}_{1}$ and $\mathrm{G}_{3}$ were directly remelted from AMTIR-2 and AMTIR-6 glasses [ㄷ] , respectively, while $\mathrm{G}_{2}$ was synthesized by mixing $\mathrm{G}_{1}$ and $\mathrm{G}_{3}$. Finally, the annealed 10-mm- and 30-mm-diameter glass rods were cut and polished into discs for further measurements and for extrusion, respectively.

The billets used in extruding the preforms were prepared by vertically stacking discs of the appropriate materials. Three $30 \mathrm{~mm}$ diameter $15 \mathrm{~mm}$ thick discs are vertically stacked in a cylindrical billet: The bottom disc is the polymer, the second disc is the cladding $\mathrm{ChG}$, and the top disc is the core ChG. The polymer discs were prepared by thin-film-rolling technology $[22, \underline{50}]$. The billet is then heated in a stainless steel sleeve and extruded under pressure through a 12-mm-diameter circular die. The extruded preform consists of nested cylindrical shells with the bottom (top) disc in the billet corresponding to the outermost (innermost) layer. A thin polymer film (75 $\mu \mathrm{m}$ thick PEI for Preform-I and PES for Preform-II) was rolled around a section of the extruded multimaterial preform and thermally consolidated under vacuum to produce a preform with a thicker polymer jacket, which-in turn-we draw into fibers.

\section{ACKNOWLEDGMENTS}

We thank D. N. Christodoulides for helpful discussions, and G. Li and E.-H. Banaei for assistance. We are grateful to R. A. Sims, L. Shah, and M. C. Richardson for granting access to the thulium fiber laser. This work was supported by the NSF (ECCS-1002295).

\section{REFERENCES}

1. B. J. Eggleton, B. Luther-Davies, and K. Richardson, "Chalcogenide photonics," Nat. Photonics 5, 141-148 (2011).

2. J. S. Sanghera, I. D. Aggarwal, L. B. Shaw, L. E. Busse, P. Thielen, V. Nguyen, P. Pureza, S. Bayya, and F. Kung, "Applications of chalcogenide glass optical fibers at NRL," J. Optoelectron. Adv. Mater. 3, 627-640 (2001).

3. J. S. Sanghera, L. B. Shaw, and I. D. Aggarwal, "Chalcogenide glass-fiber-based mid-IR sources and applications," IEEE J. Sel. Topics Quantum Elect. 15, 114-119 (2009).

4. J. M. Harbold, F. O. Ilday, F. W. Wise, J. S. Sanghera, V. Q. Nguyen, L. B. Shaw, and I. D. Aggarwal, "Highly nonlinear As-S-Se glasses for all-optical switching," Opt. Lett. 27, 119-121 (2002).

5. J. M. Harbold, F. O. Ilday, F. W. Wise, and B. G. Aitken, "Highly nonlinear GeAsSe and GeAsSSe glasses for all-optical switching," IEEE Photon. Technol. Lett. 14, 822-824 (2002).

6. J. S. Sanghera, I. D. Aggarwal, L. B. Shaw, C. M. Florea, P. Pureza, V. Q. Nguyen, F. Kung, and I. D. Aggarwal, "Nonlinear properties of chalcogenide glass fibers," J. Optoelectron. Adv. Mater. 8, 2148-2155 (2006).

7. R. Stegeman, G. Stegeman, P. Delfyett, L. Petit, N. Carlie, K. Richardson, and M. Couzi, "Raman gain measurements and photo-induced transmission effects of germanium- and arsenic-based chalcogenide glasses," Opt. Express 14, 11702-11708 (2006).

8. J. S. Sanghera, C. M. Florea, L. B. Shaw, P. Pureza, V. Q. Nguyen, M. Bashkansky, Z. Dutton, and I. D. Aggarwal, "Non-linear properties of chalcogenide glasses and fibers," J. Non-Cryst. Solids 354, 462-467 (2008).

9. J. S. Sanghera, L. B. Shaw, P. Pureza, V. Q. Nguyen, D. Gibson, L. Busse, I. D. Aggarwal, C. M. Florea, and F. H. Kung, "Nonlinear properties of chalcogenide glass fibers," Int. J. Appl. Glass Sci. 1, 296-308 (2010)

10. A. Zakery and S. R. Elliott, Optical Nonlinearities in Chalcogenide Glasses and Their Applications (Springer-Verlag, 2007).

11. A. Tuniz, G. Brawley, D. J. Moss, and B. J. Eggleton, "Twophoton absorption effects on Raman gain in single mode $\mathrm{As}_{2} \mathrm{Se}_{3}$ chalcogenide glass fiber," Opt. Express 16, 18524-18534 (2008). 
12. G. Delaizir, J.-S. Sangleboeuf, E. A. King, Y. Gueguen, X. H. Zhang, C. Boussard-Pledel, B. Bureau, and P. Lucas, "Influence of ageing conditions on the mechanical properties of Te-As-Se fibers," J. Phys. D 42, 095405 (2009).

13. R. E. Slusher, G. Lenz, J. Hodelin, J. Sanghera, L. B. Shaw, and I. D. Aggarwal, "Large Raman gain and nonlinear phase shifts in high-purity $\mathrm{As}_{2} \mathrm{Se}_{3}$ chalcogenide fibers," J. Opt. Soc. Am. B 21, 1146-1155 (2004).

14. I. Walmsley, L. Waxer, and C. Dorrer, "The role of dispersion in ultrafast optics," Rev. Sci. Instrum. 72, 1-29 (2001).

15. G. P. Agrawal, Nonlinear Fiber Optics, 3rd ed. (Academic, 2001).

16. J. M. Dudley, G. Genty, and S. Coen, "Supercontinuum generation in photonic crystal fiber," Rev. Mod. Phys. 78, 1135-1184 (2006).

17. J. M. Dudley and J. R. Taylor, eds., Supercontinuum Generation in Optical Fibers (Cambridge University, 2010).

18. L. Brilland, F. Smektala, G. Renversez, T. Chartier, J. Troles, T. N. Nguyen, N. Traynor, and A. Monteville, "Fabrication of complex structures of holey fibers in chalcogenide glass," Opt. Express 14, 1280-1285 (2006).

19. M. El-Amraoui, G. Gadret, J. C. Jules, J. Fatome, C. Fortier, F. Désévédavy, I. Skripatchev, Y. Messaddeq, J. Troles, L. Brilland, W. Gao, T. Suzuki, Y. Ohishi, and F. Smektala, "Microstructured chalcogenide optical fibers from $\mathrm{As}_{2} \mathrm{~S}_{3}$ glass: towards new IR broadband sources," Opt. Express 18, 26655-26665 (2010).

20. B. Dabas and R. Sinha, "Dispersion characteristic of hexagonal and square lattice chalcogenide $\mathrm{As}_{2} \mathrm{Se}_{3}$ glass photonic crystal fiber," Opt. Commun. 283, 1331-1337 (2010).

21. S. A. Ray Hilton, Chalcogenide Glasses for Infrared Optics (McGraw-Hill, 2009).

22. G. Tao, A. M. Stolyarov, and A. F. Abouraddy, "Multimaterial fibers,” I. J. Appl. Glass Sci. 3, 349-368 (2012).

23. D. D. Hudson, S. A. Dekker, E. C. Mägi, A. C. Judge, S. D. Jackson, E. Li, J. S. Sanghera, L. B. Shaw, I. D. Aggarwal, and B. J. Eggleton, "Octave spanning supercontinuum in an $\mathrm{As}_{2} \mathrm{~S}_{3}$ taper using ultralow pump pulse energy," Opt. Lett. 36, 1122-1124 (2011).

24. S. W. Haruna, K. S. Limb, and H. Ahmad, "Investigation of dispersion characteristic in tapered fiber," Laser Phys. 21, 945-947 (2011).

25. K. M. Mohsin, M. S. Alam, D. M. N. Hasan, and M. N. Hossain, "Dispersion and nonlinearity properties of a chalcogenide $\mathrm{As}_{2} \mathrm{Se}_{3}$ suspended core fiber," Appl. Opt. 50, E102-E107 (2011)

26. S. D. Le, D. M. Nguyen, M. Thua, L. Bramerie, M. C. e Silva, K. Lenglé, M. Gay, T. Chartier, L. Brilland, D. Méchin, P. Toupin, and J. Troles, "Efficient four-wave mixing in an ultra-highly nonlinear suspended-core chalcogenide $\mathrm{As}_{38} \mathrm{Se}_{62}$ fiber," Opt. Express 19, B653-B660 (2011).

27. G. Tao, S. Shabahang, E.-H. Banaei, J. J. Kaufman, and A. F. Abouraddy, "Multimaterial preform co-extrusion for robust chalcogenide optical fibers and tapers," Opt. Lett. 37, 2751-2753 (2012).

28. S. Shabahang, J. J. Kaufman, D. S. Deng, and A. F. Abouraddy, "Observation of the Plateau-Rayleigh capillary instability in multi-material optical fibers,” Appl. Phys. Lett. 99, 161909 (2011).

29. J. J. Kaufman, G. Tao, S. Shabahang, D. S. Deng, Y. Fink, and A. F. Abouraddy, "Thermal drawing of high-density macroscopic arrays of well-ordered sub-5-nm-diameter nanowires," Nano Lett. 11, 4768-4773 (2011).

30. S. Shabahang, M. P. Marquez, G. Tao, M. U. Piracha, D. Nguyen, P. J. Delfyett, and A. F. Abouraddy, "Octave-spanning infrared supercontinuum generation in robust chalcogenide fiber nano-tapers using picosecond pulses," Opt. Lett. 37, 4639-4641 (2012).

31. P. Merritt, R. P. Tatam, and D. A. Jackson, "Interferometric chromatic dispersion measurements on short lengths of mono-mode optical fiber," J. Lightwave Technol. 7, 703-716 (1989).

32. G. Imeshev and M. E. Fermann, "230-kW peak power femtosecond pulses from a high power tunable source based on amplification in Tm-doped fiber," Opt. Express 13, 7424-7431 (2005).

33. M. A. Solodyankin, E. D. Obraztsova, A. S. Lobach, A. I. Chernov, A. V. Tausenev, V. I. Konov, and E. M. Dianov, "Mode-locked
$1.93 \mu \mathrm{m}$ thulium fiber laser with a carbon nanotube absorber," Opt. Lett. 33, 1336-1338 (2008).

34. K. Kieu and F. W. Wise, "Soliton thulium-doped fiber laser with carbon nanotube saturable absorber," IEEE Photon. Technol. Lett. 21, 128-130 (2009).

35. T. S. McComb, R. A. Sims, C. C. C. Willis, P. Kadwani, V. Sudesh, L. Shah, and M. Richardson, "High-power widely tunable thulium fiber lasers,” Appl. Opt. 49, 6236-6238 (2010).

36. F. Haxsen, D. Wandt, U. Morgner, J. Neumann, and D. Kracht, "Pulse characteristics of a passively mode-locked thulium fiber laser with positive and negative cavity dispersion," Opt. Express 18, 18981-18988 (2010).

37. W. Burckhardt, "Refractive index and dispersion of glasses with different degrees of linking," J. Non-Cryst. Solids 50, 173-182 (1982)

38. W. S. Rodney, I. H. Malitson, and T. A. King, "Refractive index of arsenic trisulfide,” J. Opt. Soc. Am. 48, 633-636 (1958).

39. J. Hu, C. R. Menyuk, L. B. Shaw, J. S. Sanghera, and I. D. Aggarwal, "Computational study of 3-5 $\mu \mathrm{m}$ source created by using supercontinuum generation in $\mathrm{As}_{2} \mathrm{~S}_{3}$ chalcogenide fibers with a pump at $2 \mu \mathrm{m}$," Opt. Lett. 35, 2907-2909 (2010).

40. N. Carlie, J. N. C. Anheier, H. A. Qiao, B. Bernacki, M. C. Phillips, L. Petit, J. D. Musgraves, and K. Richardson, "Measurement of the refractive index dispersion of $\mathrm{As}_{2} \mathrm{Se}_{3}$ bulk glass and thin films prior to and after laser irradiation and annealing using prism coupling in the near- and mid-infrared spectral range," Rev. Sci. Instrum. 82, 053103 (2011).

41. M. Asobe, T. Kanamori, and K. Kubodera, "Applications of highly nonlinear chalcogenide glass fibers in ultrafast all-optical switches," IEEE J. Quantum Electron. 29, 2325-2333 (1993).

42. L. B. Fu, M. Rochette, V. G. Ta'eed, D. J. Moss, and B. J. Eggleton, "Investigation of self-phase modulation based optical regeneration in single mode $\mathrm{As}_{2} \mathrm{Se}_{3}$ chalcogenide glass fiber," Opt. Express 13, 7637-7644 (2005).

43. J. Fatome, C. Fortier, T. N. Nguyen, T. Chartier, F. Smektala, K. Messaad, B. Kibler, S. Pitois, G. Gadret, C. Finot, J. Troles, F. Desevedavy, P. Houizot, G. Renversez, L. Brilland, and N. Traynor, "Linear and nonlinear characterizations of chalcogenide photonic crystal fibers," J. Lightwave Technol. 27, 1707-1715 (2009).

44. M. El-Amraoui, J. Fatome, J. C. Jules, B. Kibler, G. Gadret, C. Fortier, F. Smektala, I. Skripatchev, C. Polacchini, Y Messaddeq, J. Troles, L. Brilland, M. Szpulak, and G. Renversez, "Strong infrared spectral broadening in low-loss As-S chalcogenide suspended core microstructured optical fibers," Opt. Express 18, 4547-4556 (2010).

45. S. Shabahang, G. Tao, M. P. Marquez, D. J. Hagan, E. W. Van Stryland, P. J. Delfyett, and A. F. Abouraddy, in preparation (2013).

46. T. Kanamori, Y. Terunuma, S. Takahashi, and T. Myashita "Chalcogenide glass fibers for mid-infrared transmission," J. Lightwave Technol. 2, 607-613 (1984).

47. N. J. Pitt, G. S. Sapsford, T. V. Clapp, R. Worthington, and M. G. Scott, "Telluride glass fibres for transmission in the 8-12 micrometres waveband," Proc. SPIE 618, 124-129 (1986).

48. M. Bayindir, F. Sorin, A. F. Abouraddy, J. Viens, S. D. Hart, J. D. Joannopoulos, and Y. Fink, "Metal-insulator-semiconductor optoelectronic fibres," Nature 431, 826-829 (2004).

49. M. Bayindir, A. F. Abouraddy, O. Shapira, J. Viens, D. Saygin-Hinczewski, F. Sorin, J. Arnold, J. D. Joannopoulos, and Y. Fink, "Kilometer-long ordered nanophotonic structures by preform-to-fiber fabrication," IEEE J. Sel. Top. Quantum Electron. 12, 1202-1213 (2006).

50. A. F. Abouraddy, M. Bayindir, G. Benoit, S. D. Hart, K. Kuriki, N. Orf, O. Shapira, F. Sorin, B. Temelkuran, and Y. Fink, "Towards multimaterial multifunctional fibres that see, hear, sense and communicate," Nat. Mater. 6, 336-347 (2007).

51. C. Baker and M. Rochette, "High nonlinearity and single-mode transmission in tapered multimode $\mathrm{As}_{2} \mathrm{Se}_{3}$-PMMA fibers," IEEE Photon. J. 4, 960-969 (2012).

52. G. Brambilla, F. Xu, P. Horak, Y. Jung, F. Koizumi, N. P. Sessions, E. Koukharenko, X. Feng, G. S. Murugan, J. S. Wilkinson, and D. J. Richardson, "Optical fiber nanowires and microwires: fabrication and applications," Adv. Opt. Photon. 1, 107-161 (2009). 
53. J. J. Kaufman, G. Tao, S. Shabahang, E.-H. Banaei, D. S. Deng, X. Liang, S. G. Johnson, Y. Fink, and A. F. Abouraddy, "Structured spheres generated by an in-fibre fluid instability," Nature 487, 463-467 (2012).

54. L. G. Cohen, "Comparison of single-mode fiber dispersion measurement techniques," J. Lightwave Technol. 3, 958-966 (1985).

55. V. Page and L. Chen, "Measuring chromatic dispersion of optical fiber using time of flight and a tunable multi-wavelength semiconductor fiber laser," Opt. Commun. 265, 161-170 (2006).

56. D. Ouzounov, D. Homoelle, W. Zipfel, W. W. Webb, A. L. Gaeta, J. A. West, J. C. Fajardo, and K. W. Koch, "Dispersion measurements of microstructured fibers using femtosecond laser pulses," Opt. Commun. 192, 219-223 (2001).

57. C. Lin, L. G. Cohen, W. G. French, and H. M. Presby, "Measuring dispersion in single-mode fibers in the $1.1-1.3 \mu \mathrm{m}$ spectral region-a pulse synchronization technique," IEEE J. Quantum Electron. 16, 33-36 (1980).

58. B. Costa, D. Mazzoni, M. Puleo, and E. Vezzoni, "Phase shift technique for the measurement of chromatic dispersion in optical fibers using LED's," IEEE Trans. Microwave Theor. Tech. 30, 1497-1503 (1982).

59. T. M. Kardas and C. Radzewicz, "Broadband near-infrared fibers dispersion measurement using white-light spectral interferometry," Opt. Commun. 282, 4361-4365 (2009).

60. N. K. Berger, B. Levit, and B. Fischer, "Measurement of fiber chromatic dispersion using spectral interferometry with modulation of dispersed laser pulses," Opt. Commun. 283, 3953-3956 (2010).

61. G. Tao, H. Guo, L. Feng, M. Lu, W. Wei, and B. Peng, "Formation and properties of a noval heavy-metal chalcogenide glass doped with a high dysprosium concentration," J. Am. Ceram. Soc. 92 2226-2229 (2009).

62. http://www.amorphousmaterials.com/. 